\title{
COVID-19 and cardiovascular system-a comprehensive review
}

Ibrahim AIShahrani ${ }^{1}$, Jagadish Hosmani ${ }^{2, *}$, Vidya Gurram Shankar $^{3}$, Abdulaziz AIShahrani $^{1}$, Rafi Ahmad Togoo ${ }^{1}$, Syed M Yassin ${ }^{1}$, Shahrukh Khan ${ }^{4}$, Shankargouda Patil ${ }^{5}$

${ }^{1}$ Department of Paediatric Dentistry and Orthodontic Sciences, College of Dentistry, King Khalid University, 62529 Abha, Kingdom of Saudi Arabia

${ }^{2}$ Department of Diagnostic Dental Sciences, College of Dentistry, King Khalid University, 62529 Abha, Kingdom of Saudi Arabia

${ }^{3}$ Sree NRJV Specialists Dental Clinic, 560097 Bangalore, India

${ }^{4}$ School of Nursing and Midwifery, Faculty of Health, Deakin University, 3217 Ceelong, Australia

${ }^{5}$ Department of Maxillofacial Surgery and Diagnostic Sciences, Division of Oral Pathology, College of Dentistry, Jazan University, 45142 Jazan, Saudi Arabia *Correspondence: jhosmani@kku.edu.sa (Jagadish Hosmani)

DOI:10.31083/j.rcm2202041

This is an open access article under the CC BY 4.0 license (https://creativecommons.org/licenses/by/4.0/).

Submitted: 22 February 2021 Revised: 27 April 2021 Accepted: 28 April 2021 Published: 30 June 2021

Coronavirus disease 2019 (COVID-19), a mystified cryptic virus has challenged the mankind that has brought life to a standstill. Catastrophic loss of life, perplexed healthcare system and the downfall of global economy are some of the outcomes of this pandemic. Humans are raging a war with an unknown enemy. Infections, irrespective of age and gender, and more so in comorbidities are escalating at an alarming rate. Cardiovascular diseases, are the leading cause of death globally with an estimate of $31 \%$ of deaths worldwide out of which nearly $85 \%$ are due to heart attacks and stroke. Theoretically and practically, researchers have observed that persons with pre-existing cardiovascular conditions are comparatively more vulnerable to the COVID-19 infection. Moreover, they have studied the data between less severe and more severe cases, survivors and non survivors, intensive care unit (ICU) patients and non ICU patients, to analyse the relationship and the influence of COVID-19 on cardiovascular health of an individual, further the risk of susceptibility to submit to the virus. This review aims to provide a comprehensive particular on the possible effects, either direct or indirect, of COVID-19 on the cardiovascular heath of an individual.

\section{Keywords}

ACE2; Cardiovascular disorders; Comorbidities; COVID-19

\section{Introduction}

Coronavirus disease 2019 (COVID-19), a viral contagious infection caused by SARS-CoV-2, has led to global health emergency with devastating statistical rise in the number of positive cases worldwide. WHO reports of nearly 223 affected countries with 110,384,747 confirmed cases and 2,446,008 confirmed deaths as of 21 February 2021, depicts the magnitude of this pandemic from its first reported case dated back to 31 December 2019 [1]. The data on mounting epidemiology, possible pathogenesis, clinical manifestations are still being recorded and investigated, assisting the knowledge and literature build up. According to WHO reports, as of 18 February 2021, nearly seven different vaccines against COVID-19 have been deployed. The logistics, public acceptance are few of the critical factors that need to be addressed for successful implementation of the vaccine program. On the other hand, researchers are yet to analyse, accumulate and strategize the feasible treatment regime for the infected cases to combat this virus [2].

Adding to the present difficulties, are the alarming increase in the number of positive cases among people with comorbidities. Cardiovascular system (CVS) related conditions and disorders are seeking attention during the time of COVID-19 due to the surge in fatalities reported with cardiovascular comorbidities. This requires attention as cardiovascular disorders (CVD) are one of the leading causes of death globally and its wide prevalence among the population pleads recognition and surveillance [3]. Further, research claims to have observed influence of COVID-19 on the cardiovascular health of individuals [4]. Possible theories which are based on the pathophysiology, observation and co-relating to the previous infections of Severe Acute Respiratory Syndrome (SARS) and Middle East respiratory syndrome (MERS), have led to the assumption that this virus can have either a direct effect on the individual and their CVS or indirect effect through the drugs administered in treating the virus (Fig. 1). The relationship between the possibilities of such an alliance can only be ascertained with evidence. Therefore, this review addresses at providing a collective and comprehensive details of COVID-19 on cardiovascular health.

\section{Pathophysiological speculation of alliance between COVID-19 and CVS}

Regarding the course of the disease, we are handicapped with limited information. With the data present and corelating with available literature, we try to unravel the complex pathophysiological aspect of COVID-19 and CVS. Two major aspects, $79.5 \%$ of genetic sequence and AngiotensinConverting Enzyme 2 (ACE2) as an entry receptor are the similar features COVID-19 virus shares with SARS coronavirus (SARS-CoV) [5-12]. It is speculated that the affinity of ACE2 receptor is 10-20 times greater for SARS-CoV-2 than SARS-CoV [13]. 


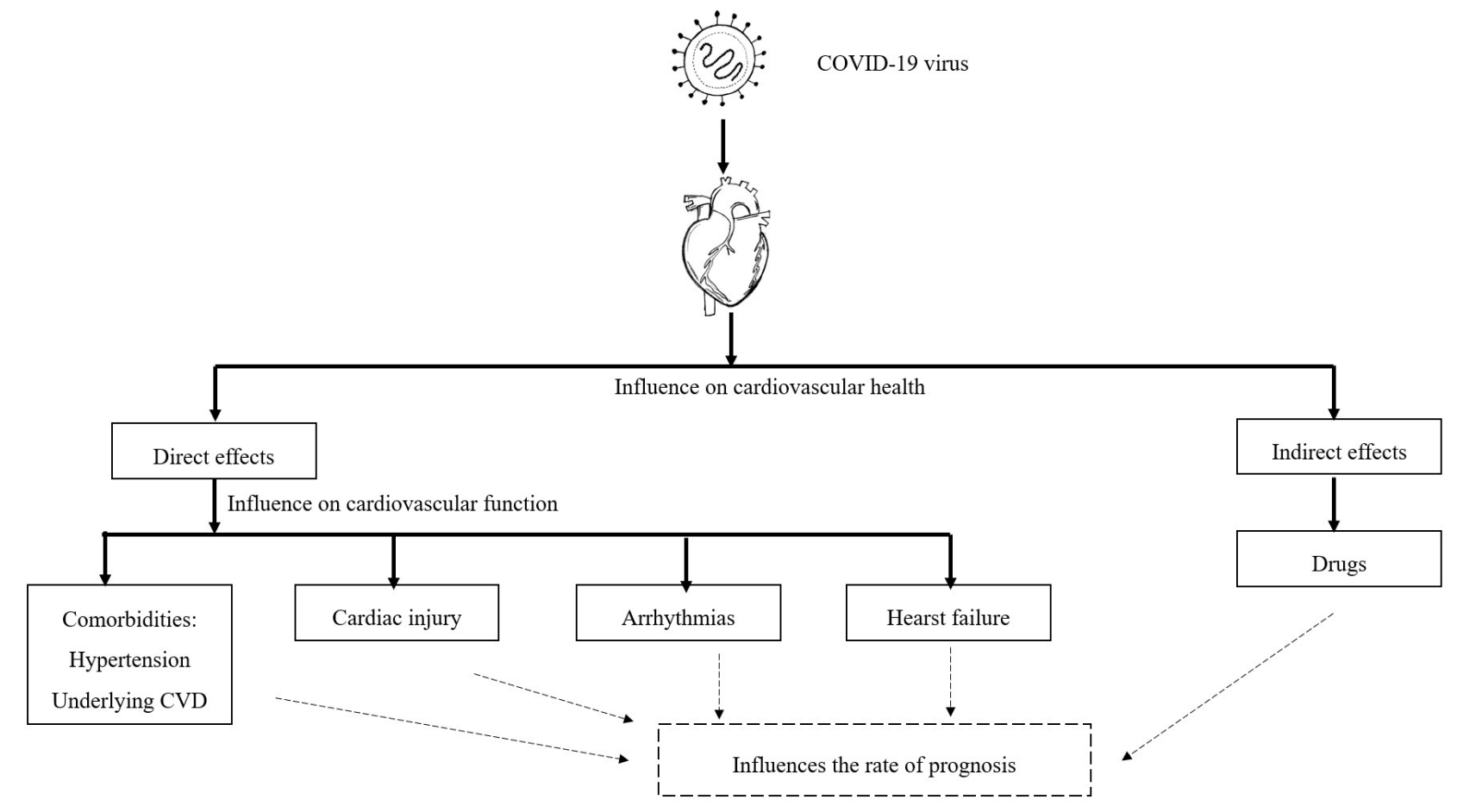

Fig. 1. Schematic representation of the possible relationship of the COVID-19 virus on the cardiovascular system.

ACE2, is known to be present in the lung, the heart, the intestinal epithelium, kidneys and even the vascular endothelium [14]. The physiological actions of ACE and ACE2 in the CVS are depicted in the Figs. 2,3. High expression of ACE2 in the heart wall to counteract angiotensin II action is well documented [11]. The possible hypothesis that we could come across from different literatures is that the virus binds to the ACE2 protein which acts as a receptor to the spike protein of the virus. This broadly results in two outcomes: (1) The ACE2 expression will be exhausted or reduced, and hence ACE2 action on the heart will be hindered. (2) The possibility of the entry of the virus into the cell through the binding to the ACE2 protein followed by endocytosis cannot be ruled out as it is the necessary for the viral replication and viral load deposition within the host [11].

This outline makes us ponder over the influence of the ACE2 on the viral infection. ACE inhibitors (ACEi) and Angiotensin II receptor blockers (ARB) are the common drugs prescribed to individuals with CVD or related comorbidities such as hypertension [15]. This leads us to speculate on the expression pattern of ACE2 under the given circumstances. Does it increase which in turn favours the entry of the virus or is hampered which again adds to the existing complications. It remains unanswered. Therefore, the yin yang relationship of ACE2 during this specific era of COVID-19 is to yet to be deduced.

Addressing the above query, a randomised clinical trial of 639 mild to moderate COVID-19 hospitalised cases who were on ACEi or ARB prior to hospitalization were enrolled and followed for a period of 30 days to determine whether dis- continuation compared to continuation of the former drugs changed the number of days alive and out of the hospital while the secondary outcomes assessed included cardiovascular death and COVID-19 progression. It was observed that there was no statistically significant difference in the number of days alive and out of the hospital in the discontinuation group when compared to the continuation group, also in COVID-19 progression or cardiovascular death between the groups. Though the study has few limitations, these findings reported do not support routinely discontinuing the former drugs in mild to moderate COVID-19 hospitalised cases if there is an indication for treatment [16]. Further, analysis of a larger population directing towards the limitations is necessary to understand the biologics to these drugs in COVID-19.

\section{Other viral infections and their relation with CVS}

MERS and SARS, are considered as the predecessors of COVID-19, reasons being similar family background, identical morphology, characteristic behaviour and clinical manifestations [17]. Literature provides with data that the presence of comorbidities and underlying CVD are complications that hinder the prognosis of a patient positive with either of these infections [18]. The prevalence of CVD in SARS was nearly $8 \%$, whose sole presence or with other comorbidities increased the mortality rate to 12 -fold, according to some studies $[19,20]$.

The possibility of direct viral cardiomyocyte damage cannot be ruled with the detection of the SARS-CoV in nearly $35 \%$ of SARS patients [21]. Hypotension, bradycardia, tachy- 


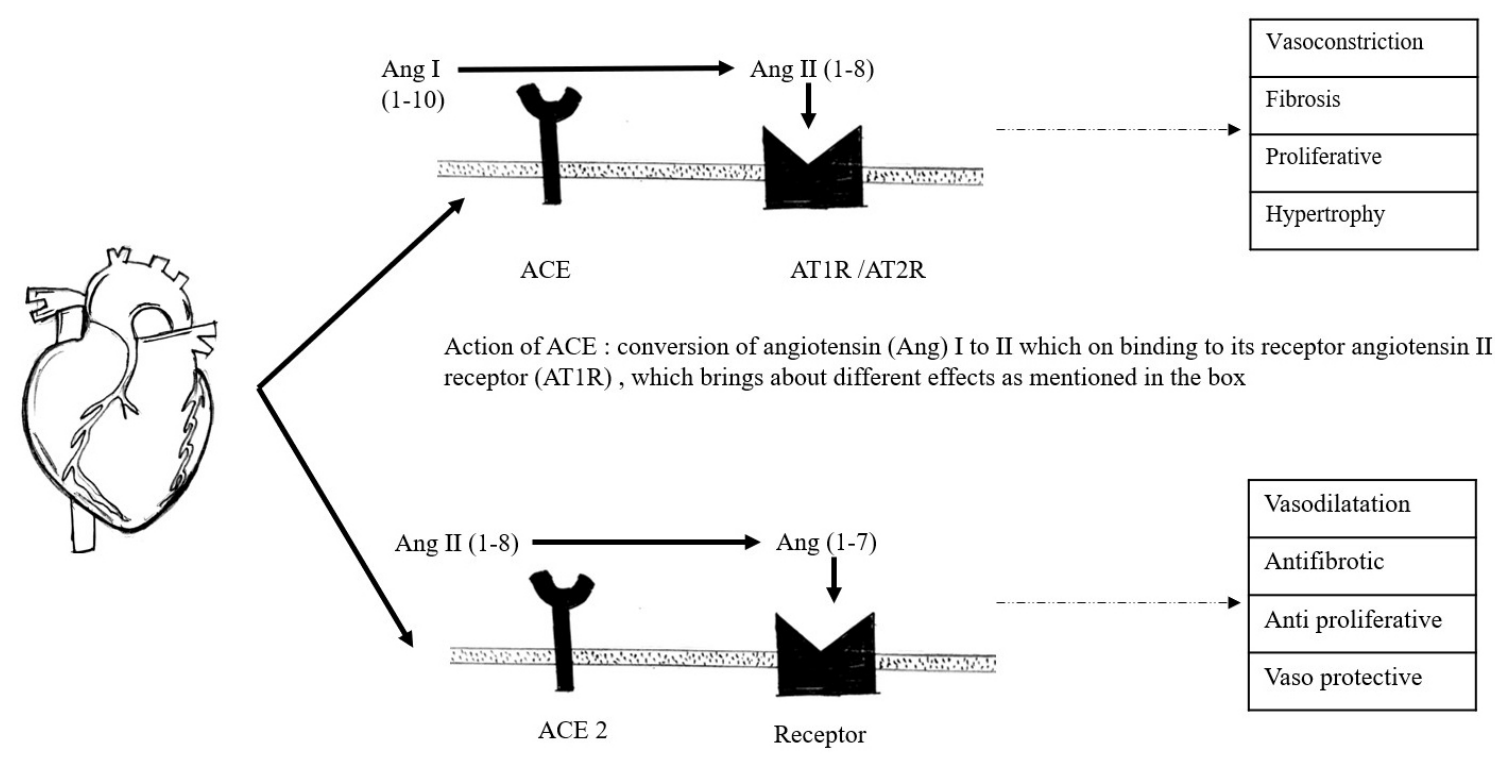

Action of ACE 2 : conversion of angiotensin (Ang) II to Ang (1-7) which on binding to its receptor, which brings about different effects as mentioned in the box

Fig. 2. Schematic representation of physiological action of ACE and ACE2 in the heart. ACE and ACE2 present with opposing actions as listed in the diagram. The actions of Angiotensin II can be further cleaved by ACE2 to bring about its effects.

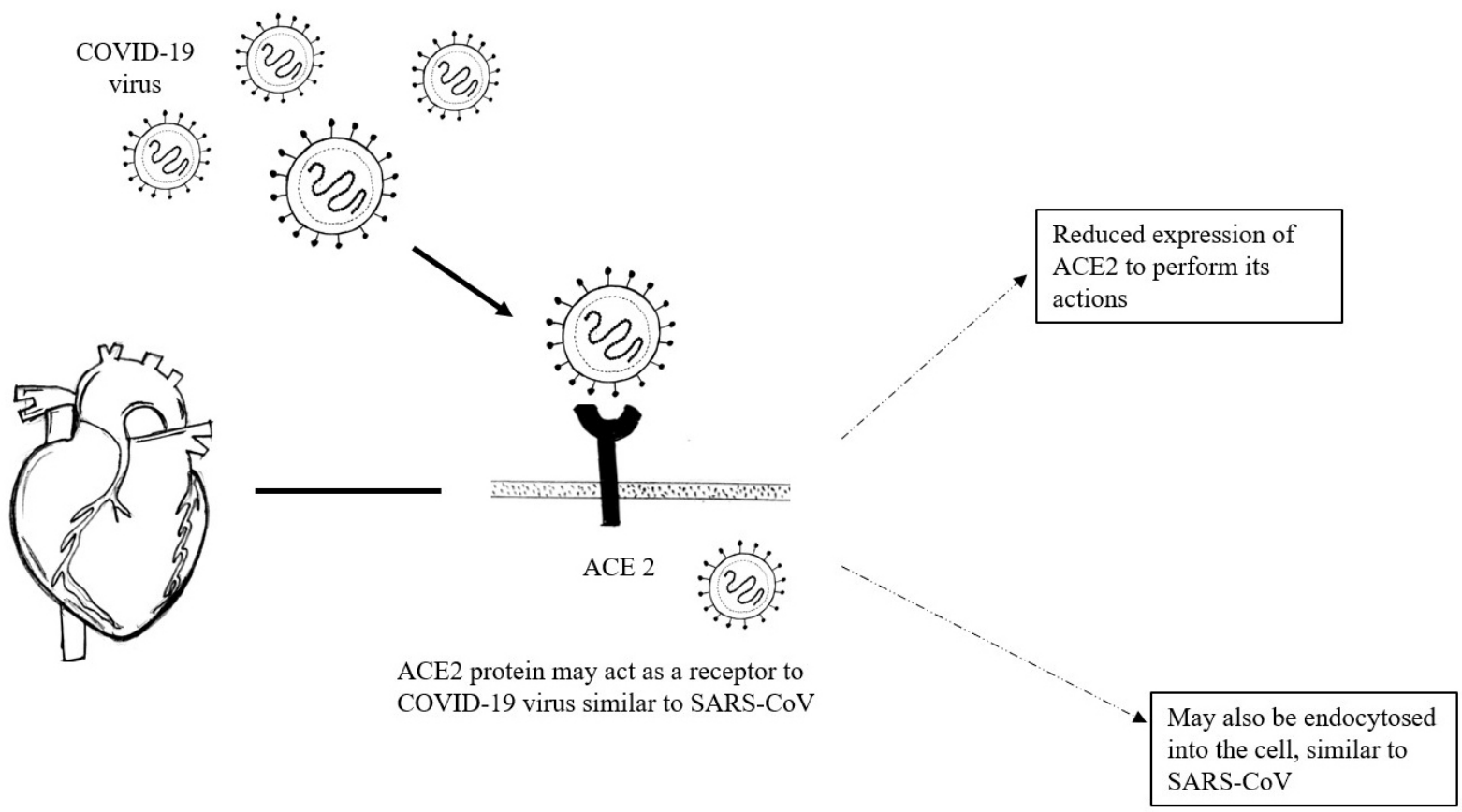

Fig. 3. Schematic representation of the possible relationship of COVID-19 virus with ACE2. ACE2, is not only present in the heart, but also the lungs, kidney, intestinal epithelium and even the vascular endothelium. The mechanism of reduced expression of ACE2 due to its binding and its possible entry into the cell are based on the similarity with SARS-CoV.

cardia, cardiomegaly, arrhythmia and even cardiac arrest were some of the cardiovascular manifestations observed by few studies during SARS [22-24]. In MERS, prevalence of hypertension in $50 \%$ cases and CVD in 30\% cases was recorded [25]. According to a case series on MERS, contributing role of myocarditis was undeniable in defining the mortality rate [26]. Other cardiovascular manifestations reported by studies on MERS were acute cardiac injury, shock, arrhythmias and acute onset heart failure [22, 27, 28]. Therefore, the relationship of COVID-19 with CVS may be similar or even pronounced as seen with MERS and SARS. 


\section{Do comorbidities en tice SARS-COV-2 virus?}

Evaluating the most vulnerable population is the initial tread in the collection of particulars with respect to any disease. Two prominent findings, older age group and population with comorbidities, are identified to be more susceptible to COVID-19 infection and its progression [28, 29]. Studies have recognised underlying diabetes, hypertension, history of coronary or lung diseases as prognosticators of infection progression [29-32]. Therefore, do CVD or its comorbidities influence COVID-19? The National health Commission of China reports a prevalence of $35 \%$ hypertension and $17 \%$ of coronary heart disease in positive cases. A recent metaanalysis of 46,248 positive cases from eight studies in China presents with nearly $17 \%$ with hypertension and more than $5 \%$ with CVD as comorbidities for COVID-19. Studies have also reported that intensive care unit (ICU) patients with positive confirmation present with comorbidities than non -ICU admitted patients [33]. Various studies reported similar findings in individuals with comorbidities who have contracted the viral infection [34-37]. A prevalence of 15\%-32.6\% and $2.5 \%-15 \%$ for hypertension and other cardiovascular disease have been reported $[38,39]$. Therefore, positive cases with CVD may present with comparatively increased adverse outcomes.

\section{Are cardiovascular complications a finding in COVID-19 infection?}

Cognizance of disturbed homeostasis and prevalent instability of an environment with viral infection is well documented of which viral infection induced systemic inflammation and increase in metabolic demand are prominent features [22]. Studies have reported both, the adverse outcomes due to underlying CVD and the viral infection itself, may be responsible or is associated with complications of CVS in COVID-19 positive individuals [40, 41]. A study reported nearly $7.2 \%-27.8 \%$ of positive patients with acute cardiac injury $[22,42], 8.7 \%$ with shock, $16.7 \%$ with arrhythmias providing evidence of the presence of $\mathrm{CV}$ complications in positive COVID-19 cases. Further, such a pronounced finding was also accompanied with an increased prevalence for the need for an ICU [43].

Various studies have reported a range of nearly $7 \%$ to $28 \%$ of COVID-19 positive hospitalized cases with cardiac injury $[29,31,38,39]$. This finding further impinges on the older and related comorbidity population $[38,39]$. On development of ARDS, a study in China has reported a median duration of 15 days for the onset of acute cardiac injury $[29,31]$. Studies have not only reported high prevalence of both electrocardiographic and echocardiographic abnormalities in positive patients, but also corelated the findings with severe disease and poor prognosis. They were also able to correlate that these findings were common in hospitalized patients [31, 34], more pronounced in ICU admissions and even more strikingly prominent in non survivors [31]. Re- cent studies have reported the development of acute cardiac injury as a sole finding, without the detection of respiratory problems [29, 44]. Shi et al. [39], reported in his case series that based on the higher mortality rate evident in hospitalized positive cases with cardiac injury than those in absence of it, could emerge as an independent prognostic variable.

Arrythmias, either unspecified [28, 29] or specific ventricular arrythmias [38] have been reported in different case series of hospitalized COVID-19 patients. Studies have reported heart failure as a complication and also a reason for mortality among COVID-19 patients [44-46]. According to Zhou et al. [31], heart failure was recorded in nearly $23 \%$ of positive cases. Further, studies have also analysed that it could be a sole reason for death in the absence of respiratory failure [26]. Supporting the data, the China NHC has reported a surge in troponin levels or cardiac arrest in hospitalized patients without any known CVD [16, 41].

Further, reports do suggest the destabilisation of the coronary plaque and the subsequent myocardial infarction may be the result of inflammation due to the COVID-19 [43]. Literature also reports of the presence of interstitial mononuclear inflammatory infiltrate within the myocardial tissue in COVID-19 patients, thereby providing evidence for myocarditis [47]. On the contrary, few case series from severely ill COVID-19 patients in Seattle, have reported absence of cardiac dysfunction by echocardiogram [48]. However, studies on their presence and role as a prognostication factor have to be further delineated.

\section{Cardiac biomarkers: a supporting evidence}

Markers which relate to disease identification, progression, analysis of severity are considered to be ideal for evaluation. Studies have reported with a steady increase in inflammation markers, coagulation and cardiac markers in individuals during the course of the infection [38, 39]. Higher mortality rate was related to active surge in troponin levels. According to the results of a systematic review and metaanalysis conducted by Jing-Wei Li et al. [49], mean troponin values, creatine kinase-MB, NT-proBNP values were significantly higher in severe cases when compared to less severe ones. Aforementioned study also analysed a dynamic surge in troponin and NT-proBNP values in non survivors during their course of hospitalization while not so significant changes in survivors [49]. A meta-analysis on 17,794 patients from 56 studies explored the association between the cardiac biomarkers and the severity and mortality in COVID19 patients. They observed that patients with elevated cardiac troponin I and Aspartate aminotransferase (AST) levels were more at a risk of developing adverse outcomes. These markers may also aid in identification of high risk population [50]. However, it is important to consider other variables in addition to these markers. 


\section{Evidence provided through coagulation factors}

Disorganised coagulation system evaluated through prolonged prothrombin time, activated partial thromboplastin time were among the initial findings of hospitalised COVID19 severe cases [28, 29, 34, 51-55]. Cui et al. [56] retrospectively analysed 81 severe COVID-19 cases in ICU for coagulation parameters and lower limb vein ultrasonography. 25\% patients were reported to have developed lower limb venous thrombosis. Further, longer activated partial thromboplastin time and elevated D-dimer levels were a common observation and hence, suggestive of their role as prognosticators.

Literature reports that in COVID-19 cases, elevated Ddimer, was found in $46 \%$ of cases; was a prominent finding in non -survivors when compared to survivors; was an evident finding in ICU cases than non- ICU cases. It was also reported that a $\mathrm{D}$-dimer level on admission if greater than $1 \mathrm{mg} / \mathrm{L}$ posed an 18 times increased risk of mortality [57]. Studies have also reported that in COVID-19 cases with high D-dimer levels, present with a comparatively lower mortality rate on treatment with heparin than those without heparin treatment [58]. The elevated D-dimer levels, being a sign of excessive coagulation activation and hyperfibrinolysis, can detect the presence of active thrombus and also can aid in monitoring the anticoagulant effectiveness. Therefore, $\mathrm{D}$-dimer may be a good indicator to detect high risk groups of venous thromboembolism. However, it is one among the various factors and hence further studies are required for better exploration [56].

Nearly 21-25\% of venous and arterial thromboembolic events were reported in COVID-19 cases, predominantly in ICU patients [56]. Though studies have reported mild thrombocytopenia in 70-95\% of severe COVID-19 cases, it is reported to be an important disease prognosticator [57]. Increased lactate dehydrogenase (LDH), high ferritin concentration are some of the other evidences on coagulator factors noted in COVID-19 cases. Further, post-mortem findings have also contributed to the evidence by the detection of microvascular platelet rich thrombotic depositions among the small vessels of the lungs and other organs. Further, 71.4\% non survivors met the disseminated intravascular coagulation (DIC) criteria [52]. All the above evidence manifests that hypercoagulable state, immobilization, vascular damage, venous and arterial thrombosis suggest a low grade DIC and localised pulmonary thrombotic microangiopathy contributing to organ dysfunction in COVID-19 cases.

\section{Pronounced cardiac manifestations in COVID-19}

8.1 Acute coronary syndrome and COVID-19: a relationship to be defined

The pathophysiological link and relationship of SARSCoV-2 with acute coronary syndrome (ACS), a clinical spectrum ranging from ST-segment elevation myocardial infarction (STEMI) to non-ST-elevation myocardial infarction
(NSTEMI) or unstable angina with/without myocardial injury is yet to be defined. However, the risk of myocardial infarction (MI) in the setting of respiratory infectious diseases is well documented through retrospective and prospective studies on influenza, pneumonia, acute bronchitis and other respiratory infections. Similarly, studies have reported MI in COVID-19 cases. Post-mortem studies of acute respiratory failure (ARF) cases in such a scenario, have suggested a prevalence of $5 \%-25 \%$ of undiagnosed acute MI. The possible mechanisms postulated for MI development are: (1) Reduced oxygen supply due to severe hypoxemia in ARF leads to activated sympathetic system and hence increased heart rate, cardiac output and contractility to meet the myocardial oxygen demand [59]; (2) Destabilization of atheromatous plaques by activation of inflammatory cells due to the circulating cytokines such as TNF- $\alpha$, IL-6, IL- $1 \beta$, IL- 8 and IL-10 $[52-55,59]$ generated by the established pro-inflammatory environment exposes the thrombogenic elements, and hence thrombus formation which could lead to MI, multiple organ microangiopathy and coronary thrombosis; (3) Platelet activation through the genetic expression of these respiratory viruses have also been considered as a risk factor for MI. It is proposed that the above-mentioned mechanisms may hold true for SARS-CoV-2 and acute MI too [59].

\subsection{COVID-19 with STEMI with and without obstructive CAD}

A systematic review by C Diaz-Arocutipa et al. [60] analysed 35 case reports and 7 case series of COVID-19 positive patients with STEMI, where differences with and without obstructive coronary artery disease (CAD) were evaluated in patients on coronary angiography. While $83 \%$ had obstructive CAD; $17 \%$, a relatively high proportion of them had non obstructive CAD with diffuse distribution of STsegment elevation. Overall, the prognosis was poor across groups with $30 \%$ in-hospital mortality rate. In accordance with the above review, M. Saririan et al. [61] reported a case series where three confirmed COVID-19 positive patients with STEMI presented with negative angiographic evidence of atherothrombotic type I MI thereby suggestive of type II MI. All the three patients had patent coronary arteries on coronary angiography. Moreover, they were able to provide evidence of ischemia without thrombosis or myocarditis in the myocardial tissue on post-mortem examination of a case. Lastly, the authors state that, further systematic investigation in consecutive patients may be necessary to identify STEMI with patent coronary arteries in COVID-19 positive cases.

\subsection{Arrythmias and COVID-19}

Literature reports $44.4 \%$ of cardiac arrythmias in severely ill hospitalised COVID-19 patients, however, the type of arrythmia is not specified [62]. Multifactorial origin, comprising of cardiac injury, acute decline in cardiac hemodynamics, hypoxemia in acute respiratory distress, inflammatory environment, direct myocyte viral invasion and even usage of QT prolonging medications are proposed for the high inci- 
dence of arrythmias noted. To-date, post mortem reports have failed to provide evidence of the viral detection in the cardiac conduction tissue such as the His-Purkinje system in COVID-19 patients with cardiac arrythmias, while successful detection of the virus in the myocardial tissue by RT-PCR and electron microscopy was reported. Atrial arrythmias was the most common type with $31 \%$ electrophysiologic consults as reported at Columbia university for COVID-19 cases during the peak of the pandemic and also where mechanical ventilation was a necessity. In contrast, while atrioventricular block accounts to $12 \%$ of arrythmias, ventricular arrythmias (VA) accounted for 7\% of the consults in COVID-19 cases. Apart from structural heart diseases, ventricular tachycardia (VT) and ventricular fibrillation (VF) are considered as primary risk factors for mortality in positive cases. Few studies have also reported that SARS-CoV-2 can act as an arrhythmogenic trigger, hence precipitate arrhythmias, thereby efforts are needed to understand the pathophysiological mechanisms that link them [62-64].

\subsection{Prolonged QT and COVID-19}

Literature reports that QT $(\mathrm{QT})$ prolonging drugs, hydroxychloroquine (HCQ) and azithromycin (AZ), was a worldwide adapted initial therapy for COVID-19 cases. However, the prolonged QT interval is an established risk factor for sudden cardiac death due to cardiac arrhythmias is also well documented. Therefore, the advantages over its limitations have to considered. A Study by Bernardini et al. [65] assessed the effect of HCQ individually and in combination with AZ on QT interval and its outcome in 112 consecutive COVID-19 cases. They concluded that the combination therapy caused a significant prolongation of QT interval when compared to HCQ alone and did not record any arrhythmic fatalities thereby suggesting that the drugs may be considered safe in relation to the arrhythmic activity in COVID-19 cases. Another study by Gasperetti et al. [64] reported administration of HCQ safe for a short duration on evaluation of ECG modifications and arrhythmic events in 648 COVID-19 cases and observed modest QTc prolongation and lack of evidence of direct attributable arrhythmic deaths. O'Conell et al. [66] concluded in a retrospective cohort study on 415 COVID-19 hospitalised cases treated with HCQ/AZ therapy, that several clinical factors such as age, body mass index, heart failure, elevated creatinine and peak troponin were associated with prolonged QTc and these changes were not associated with mortality. In contrast to the above studies, Rosenberg et al., Geleris et al., Cavalcanti et al. studies have provided evidence of increased risk of cardiac arrest with prolonged QT interval on HCQ/AZ therapy in COVID19 cases suggesting that the treatment regimen lacks efficacy and hence terminate their usage in COVID-19 cases [63]. Therefore, numerous factors have to be considered in decision making.

\section{COVID-19 therapeutics influence on CVS}

Drug repurposing/repositioning is the current treatment strategy followed by the medical fraternity to control the viral load and provide symptomatic treatment for COVID-19. Adverse CVS effects due to the therapeutics administered cannot be ruled out.

Arresting viral genome replication is considered to be a priority to restrict or inhibit its housing within the cells. Remdesivir, is the most widely studied drug based on its role during Ebola epidemic whose mechanism is to combat the replication by blocking the incorporation of nucleotides to the viral RNA strand [67-69]. Though its behaviour and interactions with other drugs are yet to be recorded and evaluated, the possibility of hypotension and cardiac arrest cannot be ruled out as reported after a loading dose in an Ebola case $[5,69,70]$.

Lopinavir/ritonavir are the common antiviral drugs used in the treatment of HIV by inhibiting the viral replication [71]. However, their use may result in prolongation of QT and PR leads interval, affect anticoagulant dosing which might require either reduction or emission of drugs such as rivaroxaban $[72,73]$. Possibility of myopathy due to its reaction with statins group of drugs like lovastatin puts the medical fraternity on alert during its use for COVID-19. Ribavirin, another antiviral drug administered in Hepatitis C, has been recorded to present with variable effects on warfarin dosing [74].

Chloroquine and Hydroxychloroquine, well established antimalarial drugs do present with myocardial toxicity [5, 14]. Another drug administered with possibility for development of hypertension and interaction with warfarin is methylprednisolone [5].

Antibiotics, such as azithromycin, vancomycin used to combat secondary bacterial infections are medications with side effects on CVS, such as arrhythmias, hypotension to name a few [75].

Apart from the drugs administered to combat the viral infection, the very existing comorbidities and the CVD pose a challenge as the regular administration of the cardiovascular drugs may complicate the drug dosage, interactions and their effectiveness. Further, the presence of sodium in some of the formulations itself needs to be monitored, most importantly in in heart failure patients [76]. These hinderances puts the medical fraternity on toes for constant monitoring and devising individual treatment plan based on the patients underlying condition, the action of the drugs and patient's reaction, the contraindications and complications associated.

\section{Mullidrug treatment for high-risk SARS-CoV-2 infection}

Studies report that initial stage of SARS-CoV-2 infection provides an opportunity through sequenced multidrug therapy (SMDT) to check the viral replication and reduce the risk of progression to severe sequelae in high-risk patients. This mode of treatment with an acceptable benefit to risk 
profile could prevent hospitalization and emergency situation especially in high-risk individuals. Researchers state that early and prompt initiation of SMDT is currently the only widely available solution comprising of (1) adjuvant nutraceuticals such as vitamin C, vitamin D; (2) anti-infective therapy including antivirals like ivermectin, hydroxychloroquine, favipiravir, and antibiotics such as azithromycin and doxycycline; (3) inhaled or oral corticosteroids like budesonide, dexamethasone (4) antiplatelet or anticoagulants like aspirin, apixaban and (5) supportive care. This therapeutic mode developed empirically based upon pathophysiology and evidence from randomised data have proved to be effective in reducing hospitalization, avoid progression to cardiovascular complications, reduced risk of cardiac injury and thereby decreased mortality $[77,78]$.

\section{Conclusions}

Though, we face a dearth of literature to back the assumptions and possibilities, inductive reasoning with the data available are the best guidance for decoding and understanding the possible influences of COVID-19 on cardiovascular health of an individual. This is the need of the hour, which helps in early recognition of the vulnerable population, recognising the action and reaction of the body to the viral load, gauging the benefits over the damage during selection of therapeutics in this war against COVID-19.

\section{Author contributions}

Concept, design, definition of intellectual content: IA, JH \& VGS. Literature search, data acquisition, data analysis: VGS, SP, SMY \& SK. Manuscript preparation manuscript editing: JH, AA \& RAT. Manuscript review: All the authors reviewed and approved the article prior to submission.

\section{Ethics approval and consent to participate Not applicable.}

\section{Acknowledgment}

The authors extend their appreciation to the Deanship of Scientific Research at King Khalid University, Abha, Saudi Arabia for funding this work through the General Research Project under grant number (226/40).

\section{Funding}

This project was supported by the General Research Project (Grant No.: 226/40).

\section{Conflict of interest}

The authors declare no conflict of interest.

\section{Declaration}

Manuscript has been read and approved by all the authors, that the requirements for authorship as stated earlier in this document have been met, and that each author believes that the manuscript represents honest work.

\section{References}

[1] WHO. Coronavirus disease (COVID-19) pandemic. 2021. Available at: https://www.who.int/emergencies/diseases/novel-cor onavirus-2019 (Accessed: 21 February 2021).

[2] WHO. COVID-19 vaccines. 2021. Available at: https: //www.who.int/emergencies/diseases/novel-coronavirus -2019/COVID-19-vaccines (Accessed: 21 February 2021).

[3] World Health Organization. Health topics: Cardiovascular diseases. 2013. Available at: http://www.who.int/topics/cardiovas culardiseases/in/ (Accessed: 20 May 2020).

[4] Ntusi N. COVID-19 and cardiovascular disease. SA Heart Journal. 2020; 17: 10.

[5] Driggin E, Madhavan MV, Bikdeli B, Chuich T, Laracy J, BiondiZoccai $\mathrm{G}$, et al. Cardiovascular considerations for patients, health care workers, and health systems during the COVID-19 pandemic. Journal of the American College of Cardiology. 2020; 75: 2352 2371

[6] del Rio C, Malani PN. 2019 Novel Coronavirus-important information for clinicians. Journal of the American Medical Association. 2020; 323: 1039.

[7] Paules CI, Marston HD, Fauci AS. Coronavirus Infections-more than just the common cold. Journal of the American Medical Association. 2020; 323: 707.

[8] Zhou P, Yang XL, Wang XG, Hu B, Zhang L, Zhang W, et al. Discovery of a novel coronavirus associated with the recent pneumonia outbreak in humans and its potential bat origin. BioRxiv. 2020.

[9] Cohen J. Mining coronavirus genomes for clues to the outbreak's origins. Science. 2020.

[10] AlGhatrif M, Cingolani O, Lakatta EG. The Dilemma of Coronavirus Disease 2019, Aging, and Cardiovascular Disease. JAMA Cardiology. 2020; 5: 747.

[11] Clarke NE, Turner AJ. Angiotensin-converting enzyme 2: the first decade. International Journal of Hypertension. 2012; 2012: 307315.

[12] Chopra HK, Kasliwal RR, Muruganathan A, Wali M, Ram CV. COVID-19, hypertension, and cardiovascular disease. Journal of Diabetology. 2020; 11: 57.

[13] Ma L, Song K, Huang Y. Coronavirus Disease-2019 (COVID-19) and cardiovascular complications. Journal of Cardiothoracic and Vascular Anesthesia. 2020; 35: 1860-1865.

[14] Bandyopadhyay D, Akhtar T, Hajra A, Gupta M, Das A, Chakraborty S, et al. COVID-19 pandemic: cardiovascular complications and future implications. American Journal of Cardiovascular Drugs. 2020; 20: 311-324.

[15] Clerkin KJ, Fried JA, Raikhelkar J, Sayer G, Griffin JM, Masoumi A, et al. COVID-19 and cardiovascular disease. Circulation. 2020; 141: 1648-1655.

[16] Lopes RD, Macedo AV, Silva PG, Moll-Bernardes RJ, Dos Santos TM, Mazza L, et al. Effect of discontinuing vs continuing angiotensin-converting enzyme inhibitors and angiotensin II receptor blockers on days alive and out of the hospital in patients admitted with COVID-19: a randomized clinical trial. Journal of the American Medical Association. 2021; 325: 254-264.

[17] Nishiga M, Wang DW, Han Y, Lewis DB, Wu JC. COVID-19 and cardiovascular disease: from basic mechanisms to clinical perspectives. Nature Reviews Cardiology. 2020; 17: 543-558.

[18] Bonow RO, Fonarow GC, O'Gara PT, Yancy CW. Association of Coronavirus Disease 2019 (COVID-19) with myocardial injury and mortality. JAMA Cardiology. 2020; 5: 751.

[19] Chan JWM, Ng CK, Chan YH, Mok TYW, Lee S, Chu SYY, et al. Short term outcome and risk factors for adverse clinical outcomes in adults with severe acute respiratory syndrome (SARS). Thorax. 2003; 58: 686-689.

[20] Booth CM, Matukas LM, Tomlinson GA, Rachlis AR, Rose DB, Dwosh HA, et al. Clinical features and short-term outcomes of 144 patients with SARS in the greater Toronto area. Journal of the American Medical Association. 2003; 289: 2801-2809.

[21] Oudit GY, Kassiri Z, Jiang C, Liu PP, Poutanen SM, Penninger JM, 
et al. SARS-coronavirus modulation of myocardial ACE2 expression and inflammation in patients with SARS. European Journal of Clinical Investigation. 2009; 39: 618-625.

[22] Xiong T, Redwood S, Prendergast B, Chen M. Coronaviruses and the cardiovascular system: acute and long-term implications. European Heart Journal. 2020; 41: 1798-1800.

[23] Yu C, Wong RS, Wu EB, Kong S, Wong J, Yip GW, et al. Cardiovascular complications of severe acute respiratory syndrome. Postgraduate Medical Journal. 2006; 82: 140-144.

[24] Pan S, Zhang H, Li C, Wang C. Cardiac arrest in severe acute respiratory syndrome: analysis of 15 cases. Chinese Journal of Tuberculosis and Respiratory Diseases. 2003; 26: 602-605.

[25] Badawi A, Ryoo SG. Prevalence of comorbidities in the Middle East respiratory syndrome coronavirus (MERS-CoV): a systematic review and meta-analysis. International Journal of Infectious Diseases. 2016; 49: 129-133.

[26] Ruan Q, Yang K, Wang W, Jiang L, Song J. Clinical predictors of mortality due to COVID-19 based on an analysis of data of 150 patients from Wuhan, China. Intensive Care Medicine. 2020; 46: 846-848.

[27] Alhogbani T. Acute myocarditis associated with novel Middle East respiratory syndrome coronavirus. Annals of Saudi Medicine. 2016; 36: 78-80.

[28] Wang D, Hu B, Hu C, Zhu F, Liu X, Zhang J, et al. Clinical characteristics of 138 hospitalized patients with 2019 novel coronavirusinfected pneumonia in Wuhan, China. Journal of the American Medical Association. 2020; 323: 1061.

[29] Atri D, Siddiqi HK, Lang JP, Nauffal V, Morrow DA, Bohula EA. COVID-19 for the Cardiologist. JACC: Basic to Translational Science. 2020; 5: 518-536.

[30] Wu C, Chen X, Cai Y, Xia J, Zhou X, Xu S, et al. Risk factors associated with acute respiratory distress syndrome and death in patients with coronavirus disease 2019 pneumonia in Wuhan, China. JAMA Internal Medicine. 2020; 180: 934.

[31] Zhou F, Yu T, Du R, Fan G, Liu Y, Liu Z, et al. Clinical course and risk factors for mortality of adult inpatients with COVID-19 in Wuhan, China: a retrospective cohort study. The Lancet. 2020; 395: 1054-1062.

[32] Cheng Y, Luo R, Wang K, Zhang M, Wang Z, Dong L, et al. Kidney disease is associated with in-hospital death of patients with COVID-19. Kidney International. 2020; 97: 829-838.

[33] Wu Z, McGoogan JM. Characteristics of and important lessons from the coronavirus disease 2019 (COVID-19) outbreak in China. Journal of the American Medical Association. 2020; 323: 1239.

[34] Huang C, Wang Y, Li X, Ren L, Zhao J, Hu Y, et al. Clinical features of patients infected with 2019 novel coronavirus in Wuhan, China. The Lancet. 2020; 395: 497-506.

[35] Chen N, Zhou M, Dong X, Qu J, Gong F, Han Y, et al. Epidemiological and clinical characteristics of 99 cases of 2019 novel coronavirus pneumonia in Wuhan, China: a descriptive study. The Lancet. 2020; 395: 507-513.

[36] Liu K, Fang Y, Deng Y, Liu W, Wang M, Ma J, et al. Clinical characteristics of novel coronavirus cases in tertiary hospitals in Hubei Province. Chinese Medical Journal. 2020; 133: 1025-1031.

[37] Guan W, Ni Z, Hu Y, Liang W, Ou C, He J, et al. Clinical characteristics of coronavirus disease 2019 in China. New England Journal of Medicine. 2020; 382: 1708-1720.

[38] Guo T, Fan Y, Chen M, Wu X, Zhang L, He T, et al. Cardiovascular implications of fatal outcomes of patients with coronavirus disease 2019 (COVID-19). JAMA Cardiology. 2020; 5: 811.

[39] Shi S, Qin M, Shen B, Cai Y, Liu T, Yang F, et al. Association of cardiac injury with mortality in hospitalized patients with COVID-19 in Wuhan, China. JAMA Cardiology. 2020; 5: 802.

[40] Li B, Yang J, Zhao F, Zhi L, Wang X, Liu L, et al. Prevalence and impact of cardiovascular metabolic diseases on COVID-19 in China. Clinical Research in Cardiology. 2020; 109: 531-538.

[41] Zheng Y, Ma Y, Zhang J, Xie X. COVID-19 and the cardiovascular system. Nature Reviews Cardiology. 2020; 17: 259-260.
[42] Chen T, Wu DI, Chen H, Yan W, Yang D, Chen G, et al. Clinical characteristics of 113 deceased patients with coronavirus disease 2019: retrospective study. British Medical Journal. 2020; 368.

[43] Ferrari R, Di Pasquale G, Rapezzi C. Commentary: what is the relationship between COVID-19 and cardiovascular disease? International Journal of Cardiology. 2020; 310: 167-168.

[44] Inciardi RM, Lupi L, Zaccone G, Italia L, Raffo M, Tomasoni D, et al. Cardiac involvement in a patient with coronavirus disease 2019 (COVID-19). JAMA Cardiology. 2020; 5: 819.

[45] Arentz M, Yim E, Klaff L, Lokhandwala S, Riedo FX, Chong M, et al. Characteristics and outcomes of 21 critically Ill patients with COVID-19 in Washington state. Journal of the American Medical Association. 2020; 323: 1612.

[46] Hu H, Ma F, Wei X, Fang Y. Coronavirus fulminant myocarditis treated with glucocorticoid and human immunoglobulin. European Heart Journal. 2021; 42: 206-206.

[47] Xu Z, Shi L, Wang Y, Zhang J, Huang L, Zhang C, et al. Pathological findings of COVID-19 associated with acute respiratory distress syndrome. The Lancet Respiratory Medicine. 2020; 8: 420422.

[48] Bhatraju PK, Ghassemieh BJ, Nichols M, Kim R, Jerome KR, Nalla AK, et al. COVID-19 in critically ill patients in the seattle region case series. New England Journal of Medicine. 2020; 382: 2012 2022.

[49] Li JW, Han TW, Woodward M, Anderson CS, Zhou H, Chen YD, et al. The impact of 2019 novel coronavirus on heart injury: a systemic review and meta-analysis. Progress in cardiovascular diseases. 2020; 63: 518-524.

[50] Toraih EA, Elshazli RM, Hussein MH, Elgaml A, Amin M, El-Mowafy M, et al. Association of cardiac biomarkers and comorbidities with increased mortality, severity, and cardiac injury in COVID-19 patients: a meta-regression and decision tree analysis. Journal of Medical Virology. 2020; 92: 2473-2488.

[51] Deng Y, Liu W, Liu K, Fang Y, Shang J, Zhou L, et al. Clinical characteristics of fatal and recovered cases of coronavirus disease 2019 in Wuhan, China: a retrospective study. Chinese Medical Journal. 2020; 133: 1261-1267.

[52] Tang N, Li D, Wang X, Sun Z. Abnormal coagulation parameters are associated with poor prognosis in patients with novel coronavirus pneumonia. Journal of Thrombosis and Haemostasis. 2020; 18: 844-847.

[53] Sun D, Li H, Lu X, Xiao H, Ren J, Zhang F, et al. Clinical features of severe pediatric patients with coronavirus disease 2019 in Wuhan: a single center's observational study. World Journal of Pediatrics. 2020; 16: 251-259.

[54] Li G, Hu R, Gu X. A close-up on COVID-19 and cardiovascular diseases. Nutrition, Metabolism and Cardiovascular Diseases. 2020; 30: 1057-1060.

[55] Liu PP, Blet A, Smyth D, Li H. The science underlying COVID-19. Circulation. 2020; 142: 68-78.

[56] Cui S, Chen S, Li X, Liu S, Wang F. Prevalence of venous thromboembolism in patients with severe novel coronavirus pneumonia. Journal of Thrombosis and Haemostasis. 2020; 18: 14211424.

[57] Levi M, Thachil J, Iba T, Levy JH. Coagulation abnormalities and thrombosis in patients with COVID-19. The Lancet Haematology. 2020; 7: e438-e440.

[58] Schiavone M, Gasperetti A, Mancone M, Curnis A, Mascioli G, Mitacchione G, et al. Anticoagulation and clinical outcomes in COVID-19: An Italian multicenter experience. International journal of cardiology. 2021; 323: 276-280.

[59] Schiavone M, Gobbi C, Biondi-Zoccai G, D'ascenzo F, Palazzuoli A, Gasperetti A, et al. Acute coronary syndromes and COVID-19: exploring the uncertainties. Journal of clinical medicine. 2020; 9: 1683.

[60] Diaz-Arocutipa C, Torres-Valencia J, Saucedo-Chinchay J, Cuevas C. ST-segment elevation in patients with COVID-19: a systematic review. Journal of thrombosis and thrombolysis. 2021; $1-8$. 
[61] Saririan M, Armstrong R, George JC, Olechowski B, O'Connor S, Byrd JB, et al. ST-segment elevation in patients presenting with COVID-19: case series. European Heart Journal-Case Reports. 2021; 5: ytaa553.

[62] Mitacchione G, Schiavone M, Gasperetti A, Forleo GB. Ventricular tachycardia storm management in a COVID-19 patient: a case report. European Heart Journal-Case Reports. 2020; 4: 1-6.

[63] Desai AD, Boursiquot BC, Melki L, Wan EY. Management of Arrhythmias Associated with COVID-19. Current Cardiology Reports. 2021; 23: 2 .

[64] Gasperetti A, Biffi M, Duru F, Schiavone M, Ziacchi M, Mitacchione $\mathrm{G}$, et al. Arrhythmic safety of hydroxychloroquine in COVID-19 patients from different clinical settings. EP Europace. 2020; 22: 1855-1863.

[65] Bernardini A, Ciconte G, Negro G, Rondine R, Mecarocci V, Viva $\mathrm{T}$, et al. Assessing QT interval in COVID-19 patients: safety of hydroxychloroquine-azithromycin combination regimen. International Journal of Cardiology. 2021; 324: 242-248.

[66] O'Connell TF, Bradley CJ, Abbas AE, Williamson BD, Rusia A, Tawney AM, et al. Hydroxychloroquine/Azithromycin Therapy and QT prolongation in hospitalized patients with COVID-19. JACC: Clinical Electrophysiology. 2021; 7: 16-25.

[67] Mulangu S, Dodd LE, Davey RT, Tshiani Mbaya O, Proschan M, Mukadi D, et al. A randomized, controlled trial of ebola virus disease therapeutics. New England Journal of Medicine. 2019; 381: 2293-2303.

[68] Gordon CJ, Tchesnokov EP, Feng JY, Porter DP, Götte M. The antiviral compound remdesivir potently inhibits RNA-dependent RNA polymerase from Middle East respiratory syndrome coronavirus. Journal of Biological Chemistry. 2020; 295: 4773-4779.

[69] Sheahan TP, Sims AC, Leist SR, Schäfer A, Won J, Brown AJ, et al. Comparative therapeutic efficacy of remdesivir and combination lopinavir, ritonavir, and interferon beta against MERS-CoV.
Nature Communications. 2020; 11: 222.

[70] Page RL, O’Bryant CL, Cheng D, Dow TJ, Ky B, Stein CM, et al. Drugs that may Cause or Exacerbate Heart Failure. Circulation. 2016; 134: e32-e69.

[71] Long B, Brady WJ, Koyfman A, Gottlieb M. Cardiovascular complications in COVID-19. The American Journal of Emergency Medicine. 2020; 38: 1504-1507.

[72] Chu CM, Cheng VCC, Hung IFN, Wong MML, Chan KH, Chan KS, et al. Role of lopinavir/ritonavir in the treatment of SARS: initial virological and clinical findings. Thorax. 2004; 59: 252-256.

[73] Mueck W, Kubitza D, Becka M. Co-administration of rivaroxaban with drugs that share its elimination pathways: pharmacokinetic effects in healthy subjects. British Journal of Clinical Pharmacology. 2013; 76: 455-466.

[74] DeCarolis DD, Westanmo AD, Chen Y, Boese AL, Walquist MA, Rector TS. Evaluation of a potential interaction between new regimens to treat hepatitis $\mathrm{c}$ and warfarin. Annals of Pharmacotherapy. 2016; 50: 909-917.

[75] Falagas ME, Rafailidis PI, Rosmarakis ES. Arrhythmias associated with fluoroquinolone therapy. International Journal of Antimicrobial Agents. 2007; 29: 374-379.

[76] Corrales-Medina VF, Musher DM, Shachkina S, Chirinos JA. Acute pneumonia and the cardiovascular system. Lancet. 2013; 381: 496-505.

[77] Procter BC, Ross C, Pickard V, Smith E, Hanson C, McCullough PA. Clinical outcomes after early ambulatory multidrug therapy for high-risk SARS-CoV-2 (COVID-19) infection. Reviews in Cardiovascular Medicine. 2020; 21: 611-614.

[78] McCullough PA, Alexander PE, Armstrong R, Arvinte C, Bain $\mathrm{AF}$, Bartlett RP, et al. Multifaceted highly targeted sequential multidrug treatment of early ambulatory high-risk SARS-CoV-2 infection (COVID-19). Reviews in Cardiovascular Medicine. 2020; 21: $517-530$ 